\title{
Business Process Management
}

\author{
DOI 10.1007/s12599-014-0330-8
}

\section{The Authors}

\author{
Prof. Dr. Jan vom Brocke ( $\varangle)$ \\ Department of Information Systems \\ University of Liechtenstein \\ Fürst-Franz-Josef-Strasse 21 \\ 9490 Vaduz \\ Liechtenstein \\ jan.vom.brocke@uni.li
}

Prof. Dr. Lars Mathiassen, Ph.D. Department of Computer Information Systems Georgia State University PO Box 4015 Atlanta, GA 30302-4015 USA Imathiassen@ceprin.org

Prof. Dr. Michael Rosemann Department of Information Systems Queensland University of Technology

Brisbane

Australia

m.rosemann@qut.edu.au

Published online: 2014-06-03

This article is also available in German in print and via http://www. wirtschaftsinformatik.de: vom Brocke J, Mathiassen L, Rosemann M (2014) Business Process Management. WIRTSCHAFTSINFORMATIK. doi: 10.1007/ s11576-014-0420-8.

(C) Springer Fachmedien Wiesbaden 2014
Business Process Management (BPM) is a discipline combining business and IT perspectives with the ultimate goal of improving an organization's business operations. BPM sets out to increase the effectiveness and efficiency of an organization; it is a significant contributor to overall organizational performance and competitiveness and it has become an increasingly important enabling factor of organizational innovation and transformation. Hence, BPM goes beyond the initial, cost-centered focus (e.g., Lean, Six Sigma) to help managers identify new revenue opportunities and non-monetary value-creation options (e.g., trusted, sustainable, and flexible processes).

From an academic perspective, BPM has attracted researchers from multiple, complementary disciplines exploring the organizational, technical, methodological, and cultural dimensions of company-wide and process-specific BPM capabilities. Since Michael Hammer's seminal paper, nearly 25 years have passed and our ability to model, analyze, execute, mine, and monitor various types of business processes has matured tremendously. However, the academic and professional BPM community still faces a number of challenges, not least related to the overall integration of BPM into existing managerial and technical corporate capabilities, the assessment of new design possibilities in BPM through e.g., mobile, social or cloud-technologies, and the tailoring of $\mathrm{BPM}$ to diverse purposes.

In light of this context, this special focus aims to provide insights into the latest, international research in this fascinating domain. The paper selection process has been a combination of sourcing papers from the highly competitive BPM track at the International Conference on Information Systems (ICIS 2013, Milan) and selecting papers from the pool of ongoing BISE submissions. As a result, it gives us great pleasure to introduce three papers chosen from this pool of high quality papers. The papers underwent a substantial review process and they demonstrate the variety of research conducted in this field.

A new view on BPM is provided by Daniel Beverungen, who characterizes business processes as organizational routines, i.e., he positions processes as being constrained by IT artifacts. In doing so, Beverungen contributes an interesting theoretical view on $\mathrm{BPM}$, a domain that despite the academic interest it attracts, is often still regarded as being limited in terms of theory-guided investigations. His proposed meta framework combines organizational routines and structuration theory in an attempt to explain the interplay of the design of IT, social systems, and routine-based processes.

Complementary to the routine-centered view of Beverungen, the second paper in this special focus studies process flexibility with a focus on quantifying its business value in the service sector. Maximilian Röglinger, Patrick Afflerbach, Gregor Kastner, and Felix Krause target the interesting challenge of identifying the ideal level of process flexibility using the principles of value-based process management. The applicability of the resulting optimization model is demonstrated by a case in the semi-conductor industry.

The third paper by Sigrid Schefer-Wenzl and Mark Strembeck is dedicated to improving the organizational structures complementing business processes. Process-aware information systems facilitate role concepts to address relevant organizational entities, and this paper investigates how to best model and enforce delegation policies in such systems. UML2 and a formal meta model are used to articulate the recommendations.

An interview with Reinhard Schütte, former Chief Financial Officer and Chief Information Officer of EDEKA, on the characteristics of large-scale projects and the role of process design and modeling completes this special focus. In this interview, Schütte describes the specific features of such "mega projects" and the issues he perceives related to the deployment of BPM techniques, in particular with the appropriate granularity of business process models.

We are very grateful to all authors who contributed to this special focus and who have demonstrated care and diligence in their ongoing revisions. An international team of reviewers ensured the high quality of the papers and we very much appreciate all of their detailed comments. 